\title{
Assessing psychological flexibility in test situations: The Test Anxiety Acceptance and Action Questionnaire for Adolescents
}

\author{
Cláudia P. Pires ${ }^{1}$, David W. Putwain ${ }^{2}$, Stefan G. Hofmann ${ }^{3}$, Dinis S. Martins ${ }^{1}$, Meagan B. MacKenzie ${ }^{4}$, \\ Nancy L. Kocovski ${ }^{4}$ and Maria do Céu Salvador ${ }^{1}$ \\ ${ }^{1}$ University of Coimbra, Faculty of Psychology and Educational Sciences, Portugal \\ ${ }^{2}$ School of Education, Liverpool John Moores University, UK \\ ${ }^{3}$ Department of Psychological and Brain Sciences, Boston University, USA \\ ${ }^{4}$ Department of Psychology, Wilfrid Laurier University, Ontario, Canada
}

\begin{abstract}
Acceptance-based interventions such as acceptance and commitment therapy motivated the development of measures of psychological flexibility. As an anxiety-based condition, test anxiety can be conceptualized as an experiential avoidance condition. Given the need to evaluate acceptance and action processes in test anxiety and the lack of such an instrument, the present study aimed to explore the factor structure and psychometric properties of the Test Anxiety-Acceptance and Action Questionnaire for Adolescents (TA-AAQ-A), adapted from the Social Anxiety-Acceptance and Action Questionnaire. The sample comprised 827 adolescents (12-18 years old) from 10 Portuguese schools. Confirmatory factor analysis indicated a welladjusted 12-item single-factor measure, invariant across genders. Results also showed high internal consistency and temporal stability, and good convergent validity. Findings suggest the TA-AAQ-A is a reliable and valid measure for the assessment of adolescents' psychological flexibility in test situations.
\end{abstract}

Keywords: test anxiety; acceptance; psychological flexibility; acceptance and commitment therapy; assessment; adolescents.

Evaluación de la flexibilidad psicológica en situaciones de examen: Cuestionario de Aceptación y Acción en la Ansiedad ante los Exámenes para Adolescentes.

Resumen: Las intervenciones basadas en la aceptación, como la Terapia de Aceptación y Compromiso, llevaron al desarrollo de herramientas de evaluación de la flexibilidad psicológica. La ansiedad ante los exámenes, siendo una condición basada en la ansiedad, puede ser conceptualizada como una condición de evitación experiencial. Considerando la necesidad de evaluar los procesos de aceptación y acción en la ansiedad ante los exámenes y no existiendo ningún instrumento de ese tipo, este estudio pretendió explorar la estructura factorial y las propiedades psicométricas del Cuestionario de Aceptación y Acción en la Ansiedad ante dos Exámenes para Adolescentes (CAA-AE-A), adaptado del Cuestionario de Aceptación y Acción en la Ansiedad Social. Participaron 827 adolescentes (12-18 años) de 10 escuelas portuguesas. Un Análisis Factorial Confirmatorio demostró un modelo bien ajustado, unifactorial, con 12 ítems, invariante entre géneros. Los resultados también mostraron elevada consistencia interna y estabilidad temporal, y buena validez convergente. Estos datos sugieren que el CAA-AE-A es un instrumento fiable y valido para evaluar la aceptación de la flexibilidad psicológica de los adolescentes en situaciones de examen.

Palabras clave: ansiedad ante los exámenes; aceptación; flexibilidad psicológica; terapia de aceptación y compromiso; evaluación; adolescentes.

Received: April 27, 2020; accepted: May 28, 2020

Funding: Research by the author Cláudia Pires is supported by a Ph.D. Grant (SFRH/BD/143520/2019), sponsored by the FCT (Portuguese Foundation for Science and Technology).
Corresponding author: Cláudia Pires, Center for Research in Neuropsychology and Cognitive Behavioral Intervention, Faculty of Psychology and Educational Sciences, University of Coimbra, Rua do Colégio Novo, 3000-115, Coimbra, Portugal. Email: claudia.pnpires@gmail.com 
School performance and achievement, increasingly judged on the basis of effective performance outcomes, are given paramount importance in today's society. Achieving academically can be a significant worry for students from a very early age, as it can determine future academic trajectories and career opportunities (Organization for Economic Cooperation and Development [OECD], 2017; Zeidner, 1998).

Anxiety symptoms are very common in adolescents in the school context, especially when performance is being tested (American Psychiatric Association, 2013). When occurring in test situations, this is defined as test anxiety, an intense fear or worry of negative evaluation when faced with formal evaluation of performance, which can result in negative behavioural, physiological and emotional responses (Zeidner, 1998).

Test anxiety has been widely studied and conceptualized in a number of models since the early 1950s (e.g., Atkinson \& Feather, 1966; Deffenbacher \& Hazaleus, 1985; Liebert \& Morris, 1967; Sarason \& Mandler, 1952; Spielberger \& Vagg, 1995; Wine, 1980). Despite some heterogeneous evidence regarding test anxiety's etiology and classification (Herzer, Wendt, \& Hamm, 2014), there is rather unquestionable agreement regarding its prevalence and subsequent impairment (Hembree, 1988, von der Embse et al., 2018). This becomes especially critical in adolescence, where the (ongoing) development of one's sense of self might get shaped by a number of fears and expectations including academic achievement (Salvador et al., 2017). A recent enquiry from the OECD briefed that, across its member countries, an average of $55 \%$ of adolescent students report feeling very anxious for a test even if well prepared (OECD, 2017). Empirical evidence also concluded that up to $25 \%$ percent of students, across all levels of education, report experiencing high levels of anxiety when taking tests (e.g., Putwain \& Daly, 2014; Segool et al., 2013; Thomas et al., 2017). In addition, although test anxiety levels are often higher in high-stakes examinations (von der Embse et al., 2018), they may not always be proportional to the evaluation's weight or contribution to the final grade, suggesting the interference of other psychosocial factors on this response (Putwain, 2008). Even though the existing literature focuses mainly on adults, particularly university students, the influence tests and exams exert on adolescents' lives (especially secondary school students), their mental health, and their well-being, has been largely corroborated (Leadbeater et al., 2012; Steinmayr et al., 2016; von der Embse et al., 2018).

The negative relationship between test anxiety and academic performance among adolescent students is well-established (e.g., McDonald, 2001; Putwain et al.,
2016; Seipp, 1991; Steinmayr et al., 2016), regardless of academic effort (Putwain \& Symes, 2018). At a cognitive level, intrusive thoughts such as those related to the anticipation of failure interfere with the attentional processes necessary to complete the task, which consequently blocks the student's performance (Sarason, 1988). This fear of failure and negative evaluation may, at times, be related to self-imposed or externally imposed (by parents, teachers or peers) expectations and criticisms (OECD, 2019). In line with this, students may adopt coping strategies based on escape and avoidance (Geen, 1987), such as delaying study, skipping classes or even missing tests (Salvador, 2009). Other studies have also shown that attempts to avoid thoughts and feelings might emerge as to deal with the experience of test anxiety (Cunha \& Paiva, 2012), especially due to the frequency of the intrusive and disturbing thoughts (Sarason, 1988). These avoidance strategies and behaviours may, in turn, lead to unwanted consequences such as compromised future career choices and life trajectories (Pascoe et al., 2020).

The impact of avoiding important actions or behaviours and private events (e.g., emotions, thoughts, memories) on the severity of psychopathology (e.g., anxiety) has been broadly defended (Beck et al., 1985; Eifert \& Forsyth, 2005; Hayes et al., 1999). This is central to Acceptance and Commitment Therapy (ACT; Hayes et al., 1999). ACT conceptualizes human suffering as a result of psychological inflexibility, defined as the inability to act effectively and according to valued ends, while in the presence of unpleasant thoughts, emotions or physical sensations (Hayes, 2004). This concept combines two interrelated processes, cognitive fusion and experiential avoidance (Hayes, 2004). Cognitive fusion refers to the process of overindentifying with one's internal events (e.g., thoughts, feelings, memories) and reacting to them as though they were real. In the context of ACT, cognitive fusion is described as the way thoughts about certain events blend with the real event, evoking the same emotional response (Hayes et al., 1999). Cognitive fusion leads to experiential avoidance, that is, the person's unwillingness to experience internal events, leading to the adoption of strategies to avoid, change, or control them. In fact, individuals tend to persevere on escape and control behaviours, given the short-term and immediate relief they convey (e.g., anxiety reduction) (Beck et al., 1985). In addition, inherent to human condition is high resistance to change and persistence on habits, which is reinforced by cultural impositions (Hayes et al., 1999). However, in the longterm, those same behaviours may cause the opposite effect, enhancing suffering and contributing to other psychological problems (Greco et al., 2008). 
On the opposite pole, the ACT model presents the concept of psychological flexibility, which includes psychological acceptance (Hayes \& Pankey, 2003), that is, the openness and willingness to experience private events as they are, without struggle or defence (Hayes et al., 1999). Psychological flexibility denotes fully contacting with the present moment (being mindful) as a conscious human being, and changing to or persisting on behaviours that serve valued ends (committed action) (Hayes et al., 1999). Along with the effectiveness of interventions based on Acceptance and Commitment Therapy for a number of psychopathologies and human difficulties (Hayes, 2020), the importance of treatments based on this model for children and adolescents has been progressively highlighted (Hayes \& Greco, 2008).

Deriving from the fact that a new model with new concepts requires new assessment tools, there has been a towering development of measures to assess psychological flexibility, the first being the Acceptance and Action Questionnaire (AAQ; Hayes et al., 2004) with a later second version (AAQ-II; Bond et al., 2011) to address the limitations of the first version. This instrument has been adapted to specific populations and psychopathologies, for instance, chronic pain (Chronic Pain Acceptance Questionnaire; CPAQ; McCracken et al., 2004), body image (Body Image Acceptance and Action Questionnaire; BI-AAQ; Sandoz et al., 2013), psychotic symptoms (Voices Acceptance \& Action Scale; VAAS; Shawyer et al., 2007), and social anxiety (Social Anxiety - Acceptance and Action Questionnaire; SA-AAQ; MacKenzie \& Kocovski, 2010), the latter having a recent brief 8 -item version (B-SA-AAQ; MacKenzie et al., 2017). Specifically for children and adolescents, Greco and colleagues have given important contributions, with the Avoidance and Fusion Questionnaire for Youth (AFQ-Y; Greco et al., 2008), and the Child and Adolescent Mindfulness Measure (CAMM; Greco et al., 2011). However, domain-specific measures to assess psychological flexibility in these developmental stages are practically non-existent (Coyne et al., 2008), even though specific instruments to measure this type of processes may be more sensitive to psychological conditions than more general measures, as already found for adults (e.g., MacKenzie \& Kocovski, 2010). Furthermore, prior research has supported the importance of cultivating acceptance within psychological interventions, not only with children and adolescents in general (Hayes \& Greco, 2008), but also towards test anxiety symptoms in particular (Cunha \& Paiva, 2012), suggesting the need to develop new assessment tools. In adolescents, as in adults, the use of such specific instruments could also be a key contribution to research and to clinical practice. With the aim of providing a valid instrument to assess acceptance and committed action in the presence of anxiety-related thoughts and feelings in test situations, we turned to an already existing instrument, whose reliability and validity was already established - the SA-AAQ (MacKenzie \& Kocovski, 2010). This choice was also motivated by the fact that, within the already existent measures of psychological flexibility, the SAAAQ is, to the best of our knowledge, the only one that measures acceptance in a context of anxiety, namely social anxiety. As stated before, the SA-AAQ was an adaptation of the original AAQ (Hayes et al., 2004). A principal component analysis revealed a two-factor structure but the correlation between factors $(r=.74$, $p<.01)$ and the fact that items were divided according to their valence (positive valenced items, representing action in face of social anxiety, loading on one factor, and negative valenced items, whose scores were then inverted, depicting avoidance of social anxious thoughts and feelings, loading on another) suggested that this structure could have been due to a method effect related to item valence, and led the authors to opt for a unidimensional structure. The SA-AAQ also showed an excellent internal consistency $(\alpha=.94)$, and good convergent validity with sound measures of social anxiety, mindfulness, acceptance, thought suppression and depression (MacKenzie \& Kocovski, 2010).

Therefore, the aim of the present study was to translate and adapt the Social Anxiety - Acceptance and Action Questionnaire to be suitable to address the adolescent population and the experience of anxiety in test situations, and to study its dimensional structure and invariance across genders, as well as its psychometric characteristics, namely internal consistency, temporal stability, and convergent validity. We hypothesized that this instrument would replicate the single-factor structure of the social anxiety version for adults (MacKenzie \& Kocovski, 2010), being invariant across gender groups, and that it would show good internal consistency and temporal stability. Moreover, we expected good convergent validity, namely negative correlations with measures of test anxiety and of its interference in school, and positive correlations with mindfulness skills.

\section{Method}

\section{Participants}

This study comprised a convenience sample of 827 adolescents from the general population, recruited from 10 public and private schools of Portugal centre area, from 
grades 8 to 12 . The average years of schooling was 10.17 $(S D=1.31)$. Participants' age ranged from 12 to 18 years old $(M=15.48 ; S D=1.39)$, with $493(59.60 \%)$ females and $334(40.40 \%)$ males, and mostly low and medium socioeconomic status. No gender differences were found for age $\left(t_{(823)}=.03, p=.98\right)$, school years $\left(t_{(825)}=.45\right.$, $p=.65)$, or socioeconomic status $\left(\chi_{(2)}^{2}=2.31 ; p=.32\right)$.

\section{Measures}

Test Anxiety-Acceptance and Action Questionnaire - Adolescents (TA-AAQ-A). Participants completed the experimental version of the TA-AAQ-A which intended to assess psychological flexibility in test situations regarding two dimensions, Acceptance and Action. The scale was adapted from the previous Social Anxiety - Acceptance and Action Questionnaire (SA-AAQ; MacKenzie \& Kocovski, 2010) (cf. Procedure). Some items are reverse-scored due to their negative valence formulation. After being rephrased, the 19 items from the original scale were maintained. Each item is rated on a 7-point Likert scale ranging from 1 (never true) to 7 (always true). Higher scores refer to higher levels of acceptance of test anxiety symptoms, without trying to control, avoid, or escape them, and higher levels of action even in the face of these symptoms. To explore this measure's factor structure and psychometric properties was the aim of the present study.

Reactions to Tests (RT; Sarason, 1984; Portuguese version for adolescents by Vicente, 2011). This is a 40item scale designed to measure the level of anxiety in test/exam situations. Participants report the degree to which each statement is typical of them on a 4-point Likert scale from 1 (not at all typical of me) to 4 (very typical of me), higher scores indicating higher levels of test anxiety. The original scale consists of four factors with 10 items each, Tension, Worry, Test-Irrelevant Thinking and Bodily Reactions. The Portuguese version for adolescents, the one used in this study, only retained 34 items but replicated the original four factor structure, as had the previous Portuguese version for adults (Baptista et al., 1989). It presented good Cronbach's alphas (.93 for the total score and between .75 and .90 for the factors), temporal stability, convergent validity, as well as sensitivity to treatment effects (Salvador, 2009).

In this study, the RT was used as a concurrent measure with part of the sample. Good internal consistency was found, both for the total score $(\alpha=.95)$ and for the factors (.91 for both Tension and Worry, .92 for Irrelevant Thinking and .80 for Bodily Reactions).

Sheehan Disability Scale (Sheehan, 1983; Portuguese version by Pinto-Gouveia et al., 2000). This is a 3 -item self-report measure that assesses the level of interference and impairment of current psychiatric symptoms (e.g., panic, anxiety, depression) on daily life in three interrelated domains: work/school, social life and family life. The extent to which those domains are impaired by the symptoms is reported on a 10-point Likert scale from 0 (not at all impaired) to 10 (extremely impaired). Higher scores indicate higher functional impairment in each of the three domains.

Although not validated for the Portuguese population, Pinto-Gouveia et al. (2000) translated and adapted the instrument to the Portuguese language for the assessment of social phobia. In this study, we only assessed the perception of interference of test anxiety in school (i.e., only one item), to use as a concurrent measure with part of the sample, having adapted the instructions.

Children and Adolescent Mindfulness Measure (CAMM; Greco et al., 2011; Portuguese version by Cunha et al., 2013). This is a 10-item scale that aims to assess children and adolescents' awareness of present moment, and non-judgmental and non-avoidant responses to their internal experience. Participants respond on a 5-point Likert scale ranging from 0 (never) to 4 (always). Items are reverse-scored due to their formulation. Higher scores indicate higher mindfulness skills. In the Portuguese version, the authors obtained a Cronbach's alpha of .74 in an adolescent sample. In the present study, this scale showed high internal consistency $(\alpha=.82)$.

\section{Procedure}

The items of the SA-AAQ were translated from the English language to the Portuguese language, and adapted to represent test situations and to better suit participants' age, by the first and last authors of the study. The adaptation was pilot tested on a small group of adolescents, not included in these analyses, for cognitive debriefing. The scale was then back-translated into English also by a bilingual researcher and small changes were made. The TA-AAQ-A was then applied to 30 adolescents to ensure facial validity. The experimental version was left with the initial 19 items and no other modifications were made. During translation and retroversion, the appropriate procedures were followed to ensure semantic, lexical, and functional aspects of the items as to preserve content uniformity on both versions (Hambleton et al., 2005).

All necessary permissions to the conduction of this study were obtained, from national entities, school boards, and adolescents' parents/legal guardians. Informed consent from adolescents was also obtained, ensuring the confidentiality of data and voluntary participation. 
The questionnaires were applied in a classroom setting. Only part of the sample $(N=178)$ completed the three concurrent measures. To assess temporal stability of the TA-AAQ-A, 118 of the 827 adolescents were asked to answer this instrument again, 4 to 6 weeks after the first administration. To control for possible contamination effects, the order of the instruments was counterbalanced.

All procedures performed in this study were in accordance with the ethical standards of the responsible committee on human experimentation (institutional and national) and with the 1964 Helsinki Declaration and its later amendments or comparable ethical standards. Informed consent was obtained from all individual participants included in the study.

\section{Data analysis}

Descriptive and correlation analyses were conducted using the Statistical Package for the Social Sciences (SPSS), version 22 (IBM Corp., 2013) and the confirmatory factor analysis (CFA) using Amos, version 22 (Arbuckle, 2013). Normal distribution of items was confirmed through coefficients of skewness and kurtosis $(|\mathrm{Sk}|<3$ and $|\mathrm{Ku}|<10$; Kline, 2005). Presence of outliers was analysed using Mahalanobis distance $\left(D^{2}\right)$. Descriptive statistics were conducted to explore the sample's characteristics. Low, medium and high socioeconomic statuses were differentiated using Simões' (1994) classification. Gender differences on age, school level and socioeconomic status were tested using independent sample t-tests and chi-square tests (Field, 2009). The interpretation of the effect size parameter was based on Cohen's criteria (1988), in which Cohen's $d$ values ranging from .20 to .50 are considered small, from .50 to .80 medium and greater than .80 large.

A confirmatory factor analysis (CFA) was performed to corroborate the factor structure obtained in the original version (SA-AAQ; MacKenzie \& Kocovski, 2010). Sample size used for this analysis $(N=827)$ was adequate to test model fit indices and scale validity (Tabachnick \& Fidell, 2007). The method of estimation used was Maximum Likelihood.

The overall adjustment of the model was verified using the following goodness-of-fit indices: chi-square $\left(\chi^{2}\right)$, normed chi-square $\left(\chi^{2} / \mathrm{df}\right)$, comparative fix index (CFI), goodness-of-fit index (GFI), adjusted GFI (AGFI), Tucker-Lewis index (TLI), and root mean square error of approximation (RMSEA; $90 \%$ confidence interval [CI]). According to Byrne (2010), $\chi^{2}$ values should not be significant, the value of the normed chi-square should approach to zero (values between 2 and 5 indicate an acceptable fit), CFI, GFI, AGFI and TLI should be higher than .90 , and RMSEA should be lower than .08 . For the adjustment of the model, we took into consideration the modification indices (MI).

A multi-group CFA was also conducted in order to assess the measurement invariance across gender groups. Invariance was assessed progressing from an unconstrained model (testing if the structure of the scale is invariant, with no measurement parameters constrained to be equal) to more restrictive models (i.e., a measurement weights model, with factor loadings constrained to be equal, and a measurement residuals model, with factor loadings, residuals and residual covariances constrained to be equal). We considered invariance as established when the added restrictions did not lead to a worse model fit. Given that the $\chi^{2}$ difference test is highly sensitive to sample size, statistical differences between models were assessed through the difference between comparative fit indices $(\triangle \mathrm{CFI})$, where a value equal or lower than .01 indicates strong invariance, i.e., equivalence between groups (Cheung \& Rensvold, 2002).

Scale and item reliability were explored using Cronbach's alpha calculation. Pearson correlations were computed to assess temporal stability and convergent validity with other relevant constructs (concurrent measures). According to Cohen's (1992) standards, correlations from .10 to .30 are considered small, .30 to .50 moderate and $>.50$ large.

\section{Results}

\section{Preliminary Analysis}

Results did not indicate severe violations of normal distribution ( $|\mathrm{Sk}|<3$ and $|\mathrm{Ku}|<10$; Kline, 2005). Skewness values ranged from -.69 to -2.25 , and kurtosis values ranged from -1.33 to 3.89 . We did, however, detect some outliers (occurring in $3 \%$ of the sample), but after confirming that there were no significant differences in results with and without outliers, we have decided to keep them. Furthermore, although some scholars have proposed the elimination of outliers (Marôco \& Bispo, 2003), or the transformation of variables (Tabachnick \& Fidell, 2007), others suggest that they should be kept, since they represent possible observations within general population, making results more generalizable (Hair et al., 2010).

\section{Confirmatory factor analysis}

A single factor model, as obtained in the adult version of the SA-AAQ (MacKenzie \& Kocovski, 2010), from 
Table 1. TA-AAQ-A's items' means (M), standard deviations (SD), Cronbach's alpha if item deleted, standardized regression weights (SRW) and squared multiple correlations (SMC) for the initial version (19 items); Cronbach's alpha if item deleted, standardized regression weights (SRW) and squared multiple correlations (SMC) for the final version (12 items).

\begin{tabular}{|c|c|c|c|c|c|c|c|}
\hline \multirow[b]{3}{*}{ Items } & \multirow[b]{3}{*}{$M(S D)$} & \multirow{2}{*}{\multicolumn{3}{|c|}{$\begin{array}{c}\text { TA-AAQ-A } 19 \text { items } \\
\alpha \alpha \text { total }=.91\end{array}$}} & \multicolumn{3}{|c|}{ TA-AAQ-A 12 items } \\
\hline & & & & & \multicolumn{3}{|c|}{$\alpha$ total $=.93$} \\
\hline & & $\alpha$ if deleted & SRW & SMC & $\alpha$ if deleted & SRW & SMC \\
\hline $\begin{array}{l}\text { 1. Despite feeling test-anxious at times, I am in control of } \\
\text { my life. }\end{array}$ & $4.91(1.46)$ & .91 & .44 & .19 & - & - & - \\
\hline $\begin{array}{l}\text { 2. I can still remain in a test situation, even when I feel } \\
\text { anxious. }\end{array}$ & $6.13(1.26)$ & .91 & .28 & .08 & - & - & - \\
\hline $\begin{array}{l}\text { 3. I do not miss the test nor do I give up while doing it } \\
\text { when I am feeling test-anxious. }\end{array}$ & $6.19(1.71)$ & .92 & .13 & .02 & - & - & - \\
\hline $\begin{array}{l}\text { 4. I keep on answering the test even when I feel anxious in } \\
\text { that situation. }\end{array}$ & $6.31(1.10)$ & .91 & .22 & .05 & - & - & - \\
\hline $\begin{array}{l}\text { 5. Being test-anxious makes it difficult to live a life that I } \\
\text { value. (r) }\end{array}$ & $4.52(2.01)$ & .91 & .63 & .40 & .93 & .64 & .41 \\
\hline $\begin{array}{l}\text { 6. I would gladly sacrifice important things in my life to } \\
\text { be able to stop being test-anxious. (r) }\end{array}$ & $4.95(1.90)$ & .90 & .55 & .30 & .93 & .55 & .30 \\
\hline $\begin{array}{l}\text { 7. I care too much about whether or not } I \text { feel anxious in } \\
\text { test situations. ( } r \text { ) }\end{array}$ & $4.22(1.93)$ & .90 & .77 & .60 & .93 & .77 & .59 \\
\hline $\begin{array}{l}\text { 8. I worry about not being able to control my test } \\
\text { anxiety. (r) }\end{array}$ & $4.20(2.06)$ & .90 & .79 & .63 & .93 & .78 & .61 \\
\hline $\begin{array}{l}\text { 9. I can still move towards important goals, even when I am } \\
\text { feeling anxious in test situations. }\end{array}$ & $5.57(1.44)$ & .91 & .22 & .05 & - & - & - \\
\hline $\begin{array}{l}\text { 10. My test anxiety must decrease before I can take } \\
\text { important steps in my life. (r) }\end{array}$ & $3.79(2.08)$ & .91 & .67 & .45 & .93 & .68 & .46 \\
\hline 11. My test anxiety does not interfere with the way I want to live. & $4.60(2.04)$ & .91 & .32 & .10 & - & - & - \\
\hline 12. I found myself thinking a lot about my test anxiety. (r) & $4.73(1.87)$ & .90 & .84 & .70 & .92 & .85 & .72 \\
\hline $\begin{array}{l}\text { 13. It seems like I am fighting myself about my test } \\
\text { anxiety. (r) }\end{array}$ & $4.80(1.92)$ & .90 & .88 & .77 & .92 & .89 & .78 \\
\hline $\begin{array}{l}\text { 14. I get caught up in some thoughts I have about test } \\
\text { anxiety. (r) }\end{array}$ & $4.76(1.88)$ & .90 & .82 & .68 & .92 & .83 & .69 \\
\hline $\begin{array}{l}\text { 15. I tell myself I shouldn't have certain thoughts about } \\
\text { test anxiety. (r) }\end{array}$ & $4.26(2.06)$ & .90 & .73 & .54 & .93 & .73 & .53 \\
\hline $\begin{array}{l}\text { 16. I criticize myself for having irrational or } \\
\text { inappropriate test anxiety. ( } r \text { ) }\end{array}$ & $5.06(1.95)$ & .90 & .77 & .59 & .93 & .75 & .56 \\
\hline $\begin{array}{l}\text { 17. I believe that having test-anxious thoughts is abnormal or } \\
\text { bad and I shouldn't think that way. (r) }\end{array}$ & 4.89 (1.97) & .91 & .47 & .23 & - & - & - \\
\hline $\begin{array}{l}\text { 18. I make judgments about whether my thoughts about } \\
\text { my test anxiety are good or bad. (r) }\end{array}$ & $4.89(1.85)$ & .91 & .68 & .46 & .93 & .66 & .43 \\
\hline $\begin{array}{l}\text { 19. I think I am doing something wrong when I feel } \\
\text { test-anxious. (r) }\end{array}$ & $4.50(2.02)$ & .91 & .66 & .44 & .93 & .65 & .42 \\
\hline
\end{tabular}

Note. Items in bold were retained in the final 12-item version.

which TA-AAQ-A was adapted, was tested. Seven of the items $(1,2,3,4,9,11$ and 17) showed low standardized regression weights (SRW) $(\lambda<.50)$ and low squared multiple correlations $(\mathrm{SMC})\left(R^{2}<.25\right)$ (Table 1). With the exception of item 17 , these items were formulated in the direction of behavioural non avoidance of test situations. However, except item 11, they did not refer specifically to the focus on one's values even when 
feeling test-anxious (committed action, cf. Hayes et al., 1999), but rather only to the ability to take action even when feeling test-anxious. Taking into account the low SRW and SMC values, it was decided to remove these items from subsequent analysis, proceeding with the remaining 12 items. Furthermore, this decision also follows recommendations to use brief measures when conducting research in the adolescent population (Shaw et al., 2011).

After retesting the model, the analysis of local adjustment indices revealed that all items presented SRW values above .50 and SMC values above .25 (Table 1). However, goodness of fit was still not ideal $\left(\chi_{(54)}^{2}=314.28, p<.001 ; \chi_{d f}^{2}=5.82 ; \mathrm{CFI}=.96 ; \mathrm{TLI}=.95\right.$; $\mathrm{GFI}=.94$; AGFI $=.91$; RMSEA $=.08,90 \%$ CI $[.07$, $.09])$. The analysis of modification indices (MI) pointed out the pertinence of correlating the error residuals of items 7 and 8,15 and 16, 16 and 18, and 18 and 19
(MI > 25). In the case of this study, adding these error covariances was theoretically justified given the similar content of the items (Byrne, 2010). This resulted in an improvement of the model fit. Although the chi-square value was significant $\left(\chi_{(50)}^{2}=119.67, p<.001\right)$, which is common in large sample sizes (Jöreskog \& Sörbom, 1993), model adjustment was enhanced, representing a good fit to the data $\left(\chi^{2}\right)_{d f}=3.83 ; \mathrm{CFI}=.98 ; \mathrm{TLI}=.97$; GFI $=.96$; AGFI $=.94$; RMSEA $=.06,90 \%$ CI $[.05$, $.07])$. The final model is displayed in Figure 1.

\section{Multi-group CFA for measurement invariance across gender groups}

Table 2 presents a summary of goodness-of-fit indices for measurement invariance across gender groups. Prior to conducting a multi-group CFA we confirmed goodnessof-fit for both male $(\mathrm{CFI}=.96)$ and female $(\mathrm{CFI}=.98)$

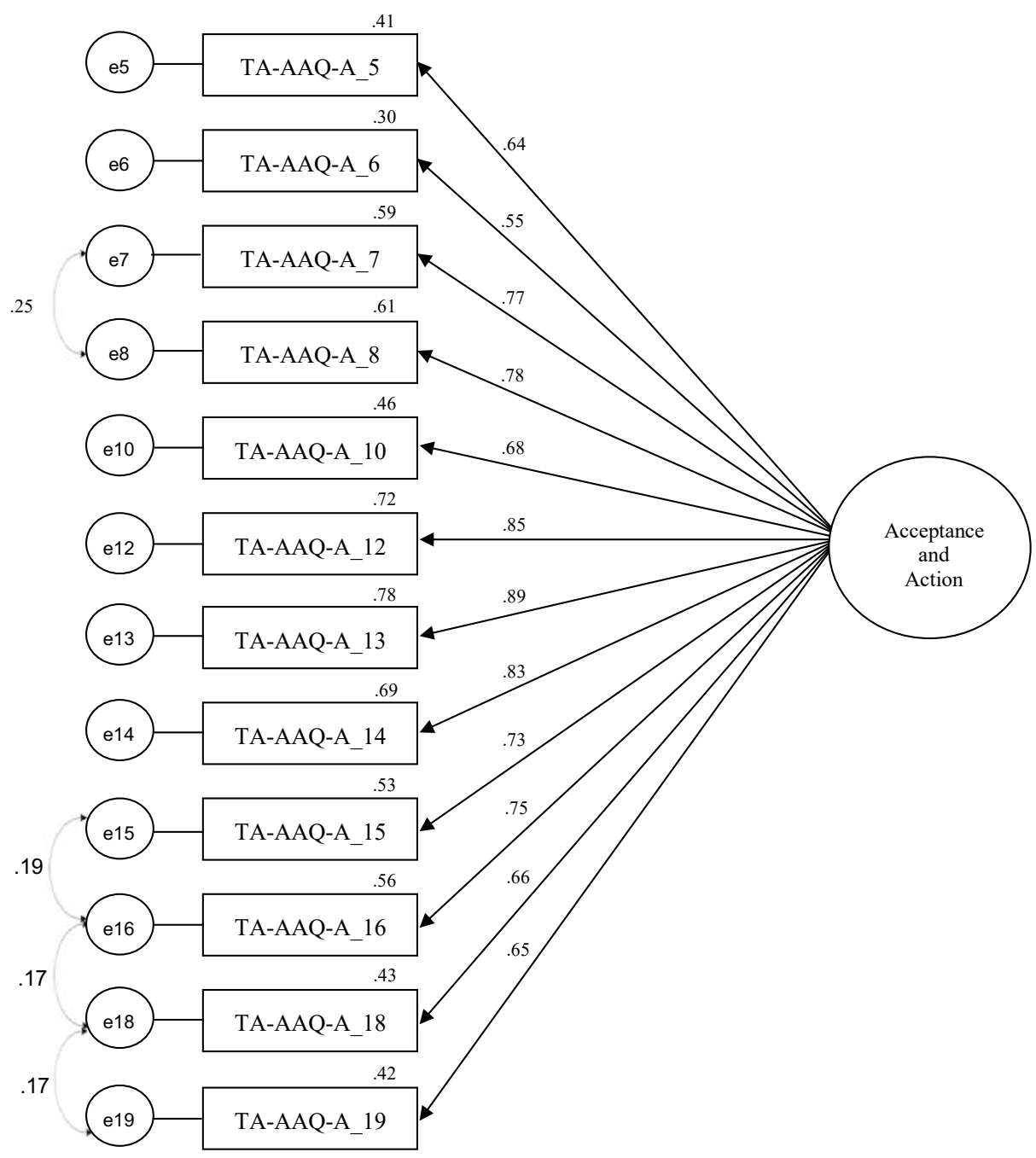

Figure 1. Final model of the Confirmatory Factor Analysis of the Test Anxiety - Acceptance and Action Questionnaire for Adolescents. 
Table 2. Summary of fit indices for measurement invariance across gender groups

\begin{tabular}{lcccccccc}
\hline & $\chi^{2}$ & $d f$ & CFI & RMSEA [90\% CI] & $\Delta \chi^{2}$ & $\Delta d f$ & $p$ & $\Delta$ CFI \\
\hline $\begin{array}{l}\text { Summary of fit statistics } \\
\text { Females }\end{array}$ & $115.89^{*}$ & 50 & .98 & $.05[.04, .06]$ & & & \\
$\quad 139.30^{*}$ & 50 & .96 & $.07[.06, .09]$ & & & \\
$\quad$ Males & & & & & & & & - \\
Multi-group analyses & $255.23^{*}$ & 100 & .97 & $.04[.04, .05]$ & - & - & - & .002 \\
$\quad$ Unconstrained model & $274.22^{*}$ & 111 & .97 & $.04[.04, .05]$ & 19.00 & 11 & .06 & .002 \\
$\quad$ Measurement weights & $351.95^{*}$ & 128 & .96 & $.05[.04, .05]$ & 77.73 & 17 & $<.001$ & .01 \\
$\quad$ Measurement residuals & &
\end{tabular}

Note. $\chi^{2}=$ chi-square goodness-of-fit statistic; $d f=$ degrees of freedom; CFI = comparative fit index; RMSEA = root mean square error of approximation. ${ }^{*} \chi^{2}$ significant at $\mathrm{p}<.001$.

groups separately, verifying a slight better model fit for the female group. The baseline unconstrained model tested the structure of the TA-AAQ-A across both gender groups simultaneously. Results showed a good model fit $(\mathrm{CFI}=.97)$, indicating that the one-factor structure model fitted the data well in both groups.

Subsequently, a measurement weights model was tested with factor loadings constrained to be equal across gender groups. This model showed a good model fit $(\mathrm{CFI}=.97)$. When compared to the baseline unconstrained model, no significant changes occurred $(\Delta \mathrm{CFI}=.002)$, indicating that the factor loadings were invariant across groups.

Finally, a measurement residuals model was tested with factor loadings, residuals and residual covariances constrained to be equal, which also showed a good model fit $(\mathrm{CFI}=.96)$. When compared to the measurement weights model, no significant changes occurred $(\Delta \mathrm{CFI}=.01)$, indicating that the residuals and residual covariances were also invariant. Still, it is important to note this parameter is commonly considered to be excessively stringent even if it presents model invariance values (Byrne, 2010).

Taking together, these results suggest that the TAAAQ-A is fit to assess acceptance and action in test situations, in both gender groups.

\section{Scale reliability and temporal stability}

Cronbach's alpha for the 12-item scale revealed a very good internal consistency $(\alpha=.93)$. Item-total correlations ranged between .62 and .84 , and the alpha value for the total scale would not improve should any of the items be removed (Table 1). To assess temporal stability, 118 adolescents were asked to complete the scale a second time, 4 to 6 weeks after the first application. A large Pearson correlation was found $(r=.58, \mathrm{p}<.01)$, suggesting high temporal stability.

\section{Convergent validity}

To assess convergent validity, correlations were computed between the TA-AAQ-A and measures of other relevant constructs: test anxiety, interference of test anxiety in school and mindfulness skills. First, it was important to test the relationship of the TA-AAQ-A with a measure of test anxiety, as the first intends to assess the degree of acceptance of symptoms that would eventually be reported in the latter. Second, since impairment in school has been denoted as one of the consequences of test anxiety (e.g., McDonald, 2001; Putwain et al., 2016; Seipp, 1991; Steinmayr et al., 2016), it would be relevant to explore the presence of acceptance of test anxiety symptoms in this equation. And third, although the concept of mindfulness is, to an extent, theoretically independent from the construct of acceptance, both are present in the concept of psychological flexibility, and so exploring the correlates of these two measures would also be appropriate. Results are displayed in Table 3. Overall,

Table 3. Convergent validity of the TA-AAQ-A with relevant measures

\begin{tabular}{cc}
\hline & TA-AAQ-A (12 items) \\
\hline RT (test anxiety) & $-.67^{* *}$ \\
RT (tension) & $-.76^{* *}$ \\
RT (worry) & $-.65^{* *}$ \\
RT (test-irrelevant thinking) & $-.33^{* *}$ \\
RT (bodily reactions) & $-.54^{* *}$ \\
SDS (interference in school) & $-.47^{* *}$ \\
CAMM (mindfulness skills) & $.47^{* *}$ \\
\hline
\end{tabular}

Note. RT $=$ Reactions to Tests; SDS $=$ Sheehan Disability Scale; $\mathrm{CAMM}=$ Children and Adolescent Mindfulness Measure.

$* * p<.01$ 
the TA-AAQ-A was revealed to be negatively correlated with test anxiety (total score and factors) and with the interference of test anxiety in school. On the other hand, TA-AAQ-A showed a positive correlation with mindfulness skills. These relationships were mainly of moderate magnitudes, which points out that, approaching Cohen's (1992) standards, the TA-AAQ-A is related to but not redundant with these variables.

\section{Descriptive Data}

Table 4 presents the mean, standard deviation and percentiles of the TA-AAQ-A for males, females and total sample, as well as the t-test to explore possible mean values differences according to gender. The t-test revealed statistically significant differences between males and females, with males reporting higher scores on the TA-AAQ-A $\left(t_{(749.90)}=-9.762, p<.01\right)$, and this effect was of medium magnitude (Cohen's $d=.69$ ). This finding is further discussed below.

\section{Discussion}

Research about the experience of feelings of anxiety when facing school evaluations, which test anxiety stands for (Zeidner, 1998), as well as evidence on the prevalence and impairing effects of this phenomenon over the last decades, seems to ascertain its underlying importance (Hembree, 1988, von der Embse et al., 2018). Given the fact that modern society is built on a performancebased culture (Smith, 2016; Zeidner, 1998), test anxiety becomes especially critical in adolescents, particularly because their future and developmental trajectory might be shaped by fears of failure and not achieving (Salvador et al., 2017).
Among test anxiety features is cognitive fusion and non-acceptance of internal events (e.g., thoughts, feelings; Cunha \& Paiva, 2012) that emerge in test situations. These two processes are conceptualized in Acceptance and Commitment Therapy (Hayes et al., 1999), consisting of an overindentification with one's thoughts concerning the test situation (taking the thoughts as if they are absolute truths) and unwillingness to experience thoughts and feelings as they are, being on the opposite pole of cognitive defusion and acceptance. This, in turn, leads to efforts to avoid, change or control these internal events, which maximizes the suffering experience (Greco et al., 2008; Hayes et al., 1999). There has been a growing development of assessment tools to appraise psychological flexibility, applied to several conditions, such as social anxiety (Social Anxiety - Acceptance and Action Questionnaire; SAAAQ; MacKenzie \& Kocovski, 2010). The aim of the present study was to develop an adaptation of the SAAAQ to adolescents in test situations. With this purpose, the items were translated to Portuguese, and adapted to this specific condition and developmental stage.

A sample of 827 adolescent students participated in the study and completed the initial version of the TAAAQ-A with 19 items. The single-factor model obtained in the SA-AAQ was tested in a Confirmatory Factor Analysis (CFA). Our first concern when observing the model referred to some items' low SRW and SMC values, specifically, items 1, 2, 3, 4, 9 and 11. After thoroughly examining their content, it was evident they were all theoretically related to the construct of committed action, featured in the ACT model (Hayes et al., 1999), although only item 11 referred to the motivation to pursue important goals despite feeling test-anxious $(M y$ test anxiety does not interfere with the way I want to

Table 4. Descriptive statistics of the TA-AAQ-A for the total sample and by gender. T-test to explore mean differences

\begin{tabular}{|c|c|c|c|c|}
\hline & & \multicolumn{3}{|c|}{ TA-AAQ-A } \\
\hline & & $\begin{array}{c}\text { Total } \\
(N=827)\end{array}$ & $\begin{array}{c}\text { Males } \\
(N=334)\end{array}$ & $\begin{array}{l}\text { Females } \\
(N=493)\end{array}$ \\
\hline Mean $(S D)$ & & $54.68(17.86)$ & $61.56(16.17)$ & $50.01(17.45)$ \\
\hline \multirow[t]{5}{*}{ Percentiles } & $5 \%$ & 25.00 & 31.75 & 23.00 \\
\hline & $25 \%$ & 40.00 & 51.00 & 36.00 \\
\hline & $50 \%$ (Median) & 55.00 & 63.00 & 49.00 \\
\hline & $75 \%$ & 70.00 & 76.00 & 63.00 \\
\hline & $95 \%$ & 82.00 & 84.00 & 79.00 \\
\hline$t_{(749.90)}$ & $-9.762 * *$ & & & \\
\hline
\end{tabular}

Note. TA-AAQ-A = Test Anxiety - Acceptance and Action Questionnaire for Adolescents. $* * p<.01$ 
live). This item might indeed be more difficult for some adolescents to understand (especially the younger ones) since it refers to more abstract and prospective selfperceptions. On the other hand, all of the other items referred simply to remaining in (not avoiding) the test situation, regardless of the undesired anxiety experience (e.g., I can remain in a test situation, even when I feel anxious [item 2]), without the motivation to pursue valued ends. Originally, these items (MacKenzie \& Kocovski, 2010) loaded in one factor that was positively phrased and that depicted non avoidance. However, when comparing these items with those in the social anxiety version of the scale (MacKenzie \& Kocovski, 2010), the latter allude to a wider range of contexts, as they cover general social situations. In our case, only testrelated (non-)avoidance was covered in these items. In addition, in the case of adolescents (i.e., students up to grade 12 ), it is very unlikely that they miss tests or leave while doing them out of feeling anxious or anticipating failure (Salvador, 2009), as most educational systems until this level consider tests as binding or crucial to the final grade and grade average (Smith, 2016). It is, for instance, more possible and probable for a university student to avoid or leave test/exam situations (Salvador, 2009), as literature has indeed uncovered (Geen, 1987). Future studies with this instrument should encompass university student samples, to explore if these items were to reveal a better adjustment in this population. However, these findings might still indicate that the TA-AAQ-A is a good measure to evaluate this specific type of anxiety, which therefore justifies the elimination of items with statements that, despite being adequate to apply to general social situations, do not apply to test situations. In addition to these items, still relatively low SRW and SMC values were found in item 17 (I believe that having test-anxious thoughts is abnormal or bad and I shouldn't think that way) $\left(\lambda=.47 ; R^{2}=.23\right)$, which is theoretically related to the construct of avoidance/acceptance in the ACT model (Hayes et al., 1999). Since this result was unforeseen, we hypothesize that this is was due to a specific manifestation of our data, which therefore might constrain possible inferential conclusions.

Regardless of the hypothesis to explain low SRW and SMC values, we made the decision of removing items $1,2,3,4,9,11$ and 17, conducting the further analysis with the remaining 12 items, which also approaches scholar recommendations for the use of brief self-report measures with adolescents (Shaw et al., 2011).

After retesting the model, and although the model fit was reasonable, we observed the presence of shared method error between certain pairs of items (items 7 and 8,15 and 16, 16 and 18, and 18 and 19). Indeed, all these pairs seemed to share similar characteristics regarding the meaning and content of the statements. The four added error covariances then resulted in an improvement of the model fit, which revealed good indices. Plus, all 12 items showed high factorial loadings and individual item reliability. The model also preserved its goodnessof-fit across genders (measurement invariance).

Therefore, the final TA-AAQ-A includes 12 reversescored items, with 9 items $(7,8,12,13,14,15,16,18$, and 19) referring mainly to the (non-)acceptance of the text anxiety experience, and 3 items $(5,6$, and 10$)$ referring mainly to (lack of) committed action, that is, the pursuit of valued ends even when experiencing test anxiety.

Still, of important note is to consider the results of the brief version of the SA-AAQ (B-SA-AAQ; MacKenzie et al., 2017). From the eight items that were retained in that version, seven of them were also retained in the 12item TA-AAQ-A (the exception being item 11), which might be a further indicator of their relevance. And although the authors found a two-factor structure in the B-SA-AAQ (Acceptance and Action), the preservation of a one-factor structure in the TA-AAQ-A is not unreasonable, since the two factors in the B-SA-AAQ were highly correlated $(r=.84)$. Furthermore, the TAAAQ-A is primarily adapted from the original SA-AAQ (MacKenzie \& Kocovski, 2010), which was also found unidimensional after a reported method effect.

The scale further proved its psychometrically sound characteristics showing high internal consistency and temporal stability.

Regarding convergent validity, the correlations between the TA-AAQ-A and relevant measures went in the expected directions. First, there was a negative and moderate correlation with the test anxiety measure, as well as with the measure of interference of test anxiety in school. These results are in line with previous studies that point out to the lack of acceptance skills in testanxious adolescents (Cunha \& Paiva, 2012), pointing out the protective effect of developing these skills to enhance adolescents' mental health and well-being in general, and to prevent or address emotional difficulties in academic settings in particular.

On the other hand, the positive correlation with the mindfulness measure extends current knowledge on the significant positive association between mindfulness and acceptance skills, which are denoted as interrelated constructs (Hayes et al., 1999; Hayes \& Strosahl, 2004).

Finally, it is important to discuss one additional finding. When testing for gender differences in the total score of the TA-AAQ-A, we found statistically significant differences between males and females, with a moderate effect size. This finding might be an indicator 
that males are possibly more accepting of their test anxiety experience than females. This result is however not entirely surprising, since previous studies have highlighted the difference between genders in measures of psychological flexibility, for instance, with females reporting higher levels of general experiential avoidance in face of anxiety symptoms (Panayiotou et al., 2017).

It is pertinent to address some of this study's limitations. Although the sample size was large and encompassed a broad age range and similar gender distribution, it cannot be considered totally representative as it was a convenience sample. Moreover, the study was conducted solely with Portuguese adolescents from the general population. Future studies should explore the structure and psychometric properties of this measure in other samples, namely adolescents from cross-cultural and clinical samples. Additionally, although retrospective recall was proven relatively reliable and stable, the reported data may be subject to current emotional states (Brewin, Andrews \& Gotlib, 1993).

Despite the stated limitations, the current study presents the TA-AAQ-A as a new reliable and sound measure for adolescents, to assess psychological flexibility in test situations, with possible implications for research and intervention purposes. Overall, these findings may cast a new light on test anxiety research, bringing the focus to acceptance and committed action processes, previously unaddressed but nonetheless relevant aspects of this phenomenon. Additionally, as formerly acknowledged, the acceptance of internal events during test situations, as well as the focus on valued ends, may constitute important targets in psychotherapy with adolescents, where the TA-AAQ-A may constitute a useful tool in assessment and in the evaluation of treatment outcome. Helping adolescents to become more willing to experience test anxious thoughts and feelings as what they are, in order to better cope with test anxiety and help them live full and valued lives, might be one lawful answer to the struggle they endure in the so-called test-conscious and performance-based society.

\section{Conflict of interest}

The authors declare that they have no conflict of interest.

\section{References}

American Psychiatric Association (2013). Diagnostic and statistical manual of mental disorders (5th ed.). Author.

Arbuckle, J. L. (2013). Amos (Version 22.0). [Computer program]. IBM SPSS.
Atkinson, J., \& Feather, N. (1966). A theory of achievement motivation. Wiley and Sons.

Baptista, A., Soczka, L., \& Pinto, A. (1989). Ansiedade dos exames: aplicação de reacções aos testes (RT) a uma amostra da população portuguesa [Exam anxiety: Aplication of reactions to tests (RT) to a sample of the portuguese population]. Psicologia, 7, 39-49. https://doi.org/10.17575/rpsicol.v7i1.754

Beck, A. T., Emery, G., \& Greenberg, M. T. (1985). Anxiety disorders and phobias. Basic Books.

Bond, F. W., Hayes, S. C., Baer, R. A., Carpenter, K. M., Guenole, N., Orcutt, H. K., Waltz, T., \& Zettle, R. D. (2011). Preliminary psychometric properties of the Acceptance and Action Questionnaire-II: A revised measure of psychological flexibility and experiential avoidance. Behavior Therapy, 42, 676-688. https://doi.org/10.1016/j.beth.2011.03.007

Brewin, C., Andrews, B., \& Gotlib, I. (1993). Psychopathology and early experience: A reappraisal of retrospective reports. Psychological Bulletin, 113, 82-98. https://doi.org/10.1037/ 0033-2909.113.1.82

Byrne, B. M. (2010). Structural equation modeling with Amos: Basic concepts, applications, and programming (2nd ed.). Taylor and Francis Group.

Cheung, G. W., \& Rensvold, R. B. (2002). Evaluating goodness-offit indexes for testing measurement invariance. Structural Equation Modeling, 9, 233-255. https://doi.org/10.1207/ S15328007SEM0902_5

Cohen, J. (1988). Statistical power analysis for the behavioral sciences (2nd ed.). Lawrence Earlbaum Associates.

Cohen, J. (1992). A power primer. Psychological Bulletin, 112(1), 155-159. https://doi.org/10.1037/0033-2909.112.1.155

Coyne, L., Cheron, D., \& Ehrenreich, J. (2008). Assessment of acceptance and mindfulness processes in youth. In L. A. Greco \& S. C. Hayes (Eds.), Acceptance \& mindfulness treatments for children and adolescents: A practitioner's guide (pp. 37-62). New Harbinger Publications.

Cruz, J. F. (1989). Incidência, desenvolvimento e efeitos da ansiedade aos exames nos testes e exames escolares [Incidence, development and effects of test anxiety in tests and school exams]. Revista Portuguesa de Educação, 2, 111-130.

Cunha, M., Galhardo, A., \& Pinto-Gouveia, J. (2013). Child and Adolescent Mindfulness Measure (CAMM): Psychometric properties of the Portuguese version. Psicologia: Reflexão $e$ Critica, 26(3), 459-468. https://doi.org/10.1590/S010279722013000300005

Cunha, M. \& Paiva, M. (2012). Text Anxiety in adolescents: The role of self-criticism and acceptance and mindfulness Skills. The Spanish Journal of Psychology, 15, 533-54. https://doi. org/10.5209/rev_SJOP.2012.v15.n2.38864

Deffenbacher, J. L., \& Hazaleus, S. L. (1985). Cognitive, emotional, and physiological components of test anxiety. Cognitive Therapy and Research, 9, 169-180. https://doi.org/10.1007/ BF01204848

Eifert, G. H., \& Forsyth, J. P. (2005). Acceptance \& commitment therapy for anxiety disorders: A practitioner's treatment guide to using mindfulness, acceptance, and values-based behaviour change strategies. New Harbinger Publications.

Field, A. (2009). Discovering Statistics Using IBM SPSS Statistics (3rd ed.). London: SAGE Publications.

Fornell, C., \& Larcker, D. F. (1981). Evaluating structural equation models with unobservable variables and measurement error. 
Journal of Marketing Research, 18, 39-50. https://doi. org/10.2307/3151312

Geen, R. G. (1987). Test anxiety and behavioral avoidance. Journal of Research in Personality, 21, 481-488.

Greco, L. A., Baer, R. A., \& Smith, G. T. (2011). Assessing mindfulness in children and adolescents: Development and validation of the Child and Adolescent Mindfulness Measure (CAMM). Psychological Assessment, 23, 606-614. https://doi. org/10.1037/a0022819

Greco, L. A., Lambert, W., \& Baer, R. A. (2008). Psychological inflexibility in childhood and adolescence: Development and evaluation of the Avoidance and Fusion Questionnaire for Youth. Psychological Assessment, 20, 93-102. https://doi. org/10.1037/1040-3590.20.2.93

Hair, J. F., Black, W. C., Babin, B. J., \& Anderson, R. E. (2010). Multivariate data analysis (7th ed.). Prentice Hall.

Hambleton, R. K., Merenda, P. F., Spielberger, C. D. (2005). Adapting educational and psychological tests for cross-cultural assessment. Lawrence Erlbaum Associates.

Hayes, S. C. (2004). Acceptance and commitment therapy, relational frame theory, and the third wave of behavioral and cognitive therapies. Behavior Therapy, 35, 639-665. https://doi.org/10. 1016/j.beth.2016.11.006

Hayes, S. C. (2020, February). ACT randomized controlled trials since 1986. Association for Contextual Behavioral Science. https:// contextualscience.org/ACT_Randomized_Controlled_Trials

Hayes, S. C. \& Greco, L, A. (2008). Acceptance and mindfulness for youth: it's time. In Laurie, A. Greco \& Steven, C. Hayes, (Eds.) Acceptance \& mindfulness treatments for children and adolescents: A practitioner's guide (pp. 3-13). New Harbinger Publications.

Hayes, S. C., \& Pankey, J. (2003). Acceptance. In W. O’Donohue, J. E. Fisher \& S. C. Hayes (Eds.), Cognitive behavior therapy: Applying Empirically Supported Techniques in your Practice (pp. 4-9). Wiley \& Sons.

Hayes, S., \& Strosahl, K. (2004). A practical guide to acceptance and commitment therapy. Springer Science.

Hayes, S.C., Strosahl, K.D., \& Wilson, K.G. (1999). Acceptance and commitment therapy: An experiential approach to behavior change. Guilford Press.

Hayes, S. C., Strosahl, K., Wilson, K. G., Bissett, R. T., Pistorello, J., Toarmino, D., Polusny, M. A., ... \& McCurry, S. M. (2004). Measuring experiential avoidance: A Preliminary Test of a Working Model. The Psychological Record, 54(4), 553578. https://doi.org/10.1007/BF03395492

Hembree, R. (1988). Correlates, causes, effects and treatment of test anxiety. Review of Educational Research, 58, 47-77. https://doi.org/10.3102/00346543058001047

Herzer, F., Wendt, J., \& Hamm, A. O. (2014). Discriminating clinical from nonclinical manifestations of test anxiety: A validation study. Behavior Therapy, 45, 222-231. https://doi. org/10.1016/j.beth.2013.11.001

IBM Corp. (2013). IBM SPSS statistics for windows (Version 22.0) [Computer program]. Armonk, NY: IBM Corp.

Jöreskog, K. \& Sörbom, D. (1993). LISREL 8: Structural equation modeling with the SIMPLIS Command Language. Chicago, IL: Scientific Software International Inc.

Kline, R. B. (2005). Principles and practice of structural equation modeling. Guilford Press.
Leadbeater, B., Thompson, K., \& Gruppuso, V. (2012). Cooccurring trajectories of symptoms of anxiety, depression, and oppositional defiance from adolescence to young adulthood. Journal of Clinical Child \& Adolescent Psychology, 41, 719730. https://doi.org/10.1080/15374416.2012.694608

Liebert, R., \& Morris, L. (1967). Cognitive and emotional components of test anxiety: A distinction and some initial data. Psychological Reports, 20, 975-978. https://doi.org/10.2466/ pr0.1967.20.3.975

MacKenzie, M. B., \& Kocovski, N. L. (2010). Self-reported acceptance of social anxiety symptoms: Development and validation of the Social Anxiety-Acceptance and Action Questionnaire. International Journal of Behavioral Consultation and Therapy, 6, 214-228. https://doi.org/10.1037/h0100909

MacKenzie, M. B., Kocovski, N. L., Blackie, R. A., Carrique, L. C., Fleming, J. E., \& Antony, M. M. (2017). Development of a brief version of the Social Anxiety-Acceptance and Action Questionnaire. Journal of Psychopathology and Behavioral Assessment, 39, 342-354. https://doi.org/10.1007/s10862-0169585-3

Marôco, J. \& Bispo, R. (2003). Estatística aplicada às ciências sociais e humanas [Statistics applied to social and human sciences]. Climepsi Editores.

McCracken, L. M., Vowles, K. E., \& Eccleston, C. (2004). Acceptance of chronic pain: Component analysis and a revised assessment method. Pain, 107, 159-166. https://doi.org/10.1016/ j.pain.2003.10.012

McDonald, A. S. (2001). The prevalence and effects of test anxiety in school children. Educational Psychology, 21(1), 89-101. https://doi.org/10.1080/01443410020019867

Panayiotou, G., Karekla, M., \& Leonidou, C. (2017). Coping through avoidance may explain gender disparities in anxiety. Journal of Contextual Behavioral Science, 6, 215-220. https://https://doi.org/10.1016/j.jcbs.2017.04.005

Pascoe, M. C., Hetrick, S. E., \& Parker, A. G. (2020) The impact of stress on students in secondary school and higher education. International Journal of Adolescence and Youth, 25, 104-112. https://doi.org/10.1080/02673843.2019.1596823

Organisation for Economic Cooperation and Development (OECD, 2017). PISA 2015 Results (Volume III): Students' Well-Being. Paris, Francia: OECD Publishing. https://doi.org/10.1787/ 9789264273856-en

Organisation for Economic Co-operation and Development (OECD, 2019). How is students' motivation related to their performance and anxiety? (PISA in Focus, 92). OECD Publishing. https:// doi.org/10.1787/d7c28431-en

Pinto-Gouveia, J., Cunha, M., \& Salvador, M. C. (2000). Um protocolo para a avaliação clínica da fobia social através de questionários de auto-resposta [A protocol to the clinical assessment of social phobia through self-report questionnaires]. In José Pinto Gouveia (Ed.), Ansiedade Social: da Timidez à Fobia Social [Social Anxiety: From Shyness to Social Phobia] (pp. 237-258). Quarteto.

Putwain, D. W. (2008). Do examinations stakes moderate the test anxiety-examination performance relationship?. Educational Psychology, 28, 109-118. https://doi.org/10.1080/ 01443410701452264

Putwain, D. W., \& Daly, A. L. (2014). Test anxiety prevalence and gender differences in a sample of English secondary school 
students. Educational Studies, 40, 554-570. https://doi.org/10. 1080/03055698.2014.953914

Putwain, D.W., Daly, T., Chamberlain, S., \& Saddredini, S. (2016). «Sink or swim»: buoyancy and coping in the test anxiety and academic performance relationship. Educational Psychology, 36(10), 1807-1825. https://doi.org/10.1080/01443410.2015.1066493

Putwain, D. W., \& Symes, W. (2018). Does increased control effort compensate for performance debilitating test anxiety?. School Psychology Quarterly, 33, 482-491. https://doi.org/10.1037/ spq0000236

Salvador, M. C. (2009). Ser eu próprio entre os outros: Um novo protocolo de intervenção para adolescentes com fobia social generalizada [To be myself among the others: A new intervention protocol for adolescents with generalized social phobia] (Doctoral dissertation). Retrieved from https://estudogeral.sib. uc.pt/bitstream/10316/12527/3/Tese\%20Doutoramento $\% 20$ Maria\%20do\%20C\%C3\%A9u\%20Salvador.pdf

Salvador, M.C., Carona, C., Castilho, P., \& Rijo, D. (2017). Selfcriticism and self-compassion in adolescents: Two forms of self-relating and their implications for psychopathology and treatment. Clinics of Turkey-Special Edition of Child and Adolescent Psychiatry, 3, 132-138.

Sandoz, E. K., Wilson, K. G., Merwin, R. M., \& Kate Kellum, K. (2013). Assessment of Body Image Flexibility: The Body Image-Acceptance and Action Questionnaire. Journal of Contextual Behavioral Science, 2(1-2), 39-48. https://doi. org/10.1016/j.jcbs.2013.03.002

Sarason, I. G. (1984). Stress, anxiety, and cognitive interference: Reactions to tests. Journal of Personality and Social Psychology, 46, 929-938. https://doi.org/10.1037//0022-3514.46.4.929

Sarason, I. G. (1988). Anxiety, self-preoccupation and attention. Anxiety Research, 1(1), 3-7. https://doi.org/10.1080/10615808808248215

Sarason, S.B., \& Mandler, G. (1952). Some correlates of test anxiety. The Journal of Abnormal and Social Psychology, 47, 810-817. https://doi.org/10.1037/h0060009

Segool, N., Carlson, J., Goforth, A., von der Embse, N., \& Barterian, J. (2013). Heightened test anxiety among young children: elementary school students' anxious responses to high-stakes testing. Psychology in the Schools, 50, 489-499. https://doi. org/10.1002/pits.21689

Seipp, B. (1991). Anxiety and academic performance: A metaanalysis of findings. Anxiety Research, 4(1), 27-41. http:// dx.doi.org/10.1080/08917779108248762

Shaw, C., Brady, L. M., \& Davey, C. (2011). Guidelines for research with children and young people. National Children's Bureau Research Centre.
Shawyer, F., Ratcliff, K., Mackinnon, A., Farhall, J., Hayes, S. C., \& Copolov, D. (2007). The voices acceptance and action scale (VAAS): Pilot data. Journal of Clinical Psychology, 63, 593606. https://doi.org/10.1002/jclp.20366

Sheehan, D. V. (1983). The Sheehan Disability Scales. In D. V. Sheehan (Ed.), The Anxiety Disease (p. 151). Charles Scribner and Sons.

Simões, M. R. (1994). Investigações no âmbito da aferição nacional do Teste das Matrizes Progressivas Coloridas de Raven (M.P.C.R.). [Research on national aferition of Raven's Coloured Progressive Matrices (R.C.P.M.)] (Unpublished doctoral dissertation). Faculty of Psychology and Education Sciences, University of Coimbra, Portugal.

Smith, W. C. (2016). Exploring accountability: National testing policies and student achievement. In T. Burns and F. Köster (Eds.), Governing Education in a Complex World. OECD Publishing. https://doi.org/10.1787/9789264255364-6-en

Spielberger, C. D., \& Vagg, P. R. (1995). Text anxiety: A transactional process model. In C. D. Spielberger e P. R. Vagg (Eds.), Text Anxiety: Theory, Assessment, and Treatment (pp. 3-14). Taylor $\&$ Francis.

Steinmayr, R., Crede, J., McElvany, N., \& Wirthwein, L. (2016). Subjective well-being, test anxiety, academic achievement: Testing for reciprocal effects. Frontiers in Psychology, 6, 1994. https://doi.org/10.3389/fpsyg.2015.01994

Tabachnick, B. G., \& Fidell, L. S. (2007). Using multivariate statistics (5th ed.). Pearson Education, Inc.

Thomas, C. L., Cassady, J. C., \& Finch, W. H. (2017). Identifying severity standards on the cognitive test anxiety scale: Cut score determination using latent class and cluster analysis. Journal of Psychoeducational Assessment, 36, 492-508. https://doi. org/10.1177/0734282916686004

Vicente,A. R. F. (2011). O Reações aos Testes (RT): estudos de validação numa amostra de adolescentes Portuguesa [The Reactions to Tests (RT): Validation studies in a sample of Portuguese adolescents]. (Unpublished master's thesis). Faculty of Psychology and Education Sciences, University of Coimbra, Portugal.

von der Embse, N., Jester, D., Roy, D., \& Post, J. (2018). Test anxiety effects, predictors and correlates: A 30-year meta-analytic review. Journal of Affective Disorders, 227, 483-493. https:// doi.org/10.1016/j.jad.2017.11.048

Wine, J. D. (1980). Cognitive-attentional theory of test-anxiety. In I. G. Sarason (Ed.), Test Anxiety: Theory, Research and Applications (pp. 349-385). Lawrence Erlbaum Associates.

Zeidner, M. (1998). Text anxiety: The State of the Art. Plenum Press. 
